\title{
The Validity of the Scores of Cervical Mucus during Artificial Insemination for Estimating the Probability of Conceiving in Clinically Healthy Cows
}

\section{Atilla Yıldız}

Veterinary Department, Sivrice Vocational High School, Firat University, 23119 Elazig, Turkey.

\begin{tabular}{|c|}
\hline Abstract | Cervical mucus is a biological environme \\
\hline
\end{tabular}

\section{Introduction}

$\mathrm{C}$ ervical mucus is one of the factors which play a role in natural fertilization and also being the place for sperm capacitation (Maher et al., 2018). Cervical mucus is a biological environment that affects sperm survival and determines the ability of cows to become pregnant (Beran et al., 2013). Cervical mucus is a viscoelastic secretion produced by mucus-secreting epithelial cells of the cervix.
Cervical mucus controls survival and migration of sperm cells and serves as a chemical and physical barrier to prevent microorganism's invasion (Verma et al., 2014). Cervical mucus consists of water (9599\%), ions, enzymes, mucins, plasma proteins and bactericidal proteins (Martyn et al., 2014). The mucus is under the control of the reproductive hormones (Siregar et al., 2019). Hormonal fluctuations impact mucus production, composition and ultrastructure of mucus during the oestrus which affects sperm June 2021 | Volume 7 | Issue 1 | Page 58 
penetrability and may result in fertilization failure Nakano et al, 2015). Normally cervix secretes the clear, pure and odourless mucus (Lim et al. 2014). The structure of the cervical mucus plays an important role in the activity of the spermatozoa in the female reproductive (Sharma and Tripathi, 1987). The assessment of physical characteristics of oestrus mucus has been suggested by some researchers as an effective tool to predict fertility in cattle (Rangnekar et al., 2002). While clear and transparent cervical mucus shows normal health, reproductive disorders may result in blurred and dirty mucus (Verma et al, 2014). Some studies which relates cervical mucus with conception rate have been noticed in cattle (Bernardi et al., 2016; Hanumant et al., 2019). It has been reported that the physical property changes of cervical mucus may be related to lack of pregnancy in cows (Bernardi et al., 2016; Siregar et al., 2017; Parikh et al., 2018). Insemination based on cervical mucus characteristics may increase pregnancy rate (Modi et al., 2011). Although it is well established that the cervical mucus has a major effect in maintaining sperm function after insemination, the importance of cervical mucus in unexplained subfertility is generally underestimated (Nakano et al., 2015). Studies on the physical property of cervical mucus and its association with reproductive performance may reveal some of the inexplicable causes of subfertility in clinically normal cows. Therefore, this study's aim is to evaluate the extent to which the scores specific to the changes in physical properties of cervical mucus predict the probability of conception at insemination time.

\section{Materials and Methods}

Animals experimental animals

The study was carried out on 36 clinically healthy Holstein cows to investigate the relationship between cervical mucus characteristics and cows' ability to conceive at a private dairy farm located in Elazig province of Turkey in the summer season. The experiment was conducted in compliance with the universal ethical standards. The mean temperature was $27.3^{\circ} \mathrm{C}$ (ranging from $18.3^{\circ} \mathrm{C}$ to $35.7^{\circ} \mathrm{C}$ ) during the experiment period. Cows included in the study were clinically free of other diseases as well as reproductive disorders. Their health status was evaluated by a general clinical examination including rectal temperature, heart rate, respiratory profile, appetite, fecal consistency, and examinations of genital organs. The parity of cows ranged between and 3. The cows were between 50 and 75 days in milk. All animals were kept under similar feeding and management conditions during the experiment. Cows were housed in free-stall barns with slotted concrete floors and cubicles. Drinking water was available ad libitum. They were fed the total mixed ration (TMR) composed of corn silage and grain rations, which were balanced according to their nutritional requirements depending on milk production. The average daily milk production for the farm was between 20 to $23 \mathrm{~kg}$ per cow during the study period.

Oestrus detection and insemination

Oestrus was determined by highly qualified personne by observing the behaviour of animals twice daily for about $30 \mathrm{~min}$ before the morning $(06 \mathrm{~h})$ and afternoon $(17 \mathrm{~h})$ milking. Cows were checked for swelling or edema of vulva, reddening of vestibular mucus membrane, cervical mucus presence, and examined per rectum for uterine tonicity to confirm the visual detection of estrus. Artificial insemination (AI) was performed by rectovaginal method using commercia frozen semen by the farm veterinarian after detection of oestrus.

\section{Cervical mucus collection}

Mucus samples were obtained by mid-cervical aspiration using a cervical insemination pipette inserted into a disposable $50 \mathrm{ml}$ syringe just before AI. Prior to aspiration, the vulva was cleaned with a mild disinfectant solution to prevent contamination and dried with a paper towel; In order to prevent sample contamination, the insemination pipettes were thoroughly cleaned with alcohol and sterile water between collections. Immediately after cervica mucus collection, $5 \mathrm{~mL}$ cervical mucus was taken to the laboratory in a sterile test tube. The evaluation in laboratory was performed within $1 \mathrm{~h}$ in cervical mucus.

Assessment of cervical mucus characteristics

A revised reference score for grading cervical mucus characteristics for animals was designed according to the original recommendation of the World Health Organization (WHO, 2010).

The cervical mucus score was assigned, for each parameter i.e. colour, viscosity, spinnbarkeit, ferning crystallization), and $\mathrm{pH}$, from 0 to 3 , with a maximum cervical mucus score of 15 .
The mucus obtained immediately after aspiration was observed visually to check the appearance. Colour was determined via a scoring system based on observations.

Colour was scored as follows:

$0=\operatorname{dirty} ; 1=$ translucent $/$ cloudy; $2=$ slight cloudiness; $3=$ clear/transparent

Cervical mucus viscosity

Viscosity of mucus was graded according to the fluidity of the cervical mucus in a glass slide sloping at a $45^{\circ}$ angle (Joshi et al., 2017).

Based on WHO criteria (WHO, 2010), viscosity was scored as follows:

$0=$ thick, highly viscous; $1=$ mucus of intermediate viscosity; $2=$ mildly viscous mucus; $3=$ watery, minimally viscous.

Spinnbarkeit

We applied our modification of Verma et als scoring method to evaluate the cervical mucus $\mathrm{pH}$ (Verma et al., 2014).

Spinnbarkeit is scored as follows:

$0=<6 \mathrm{~cm} ; 1=7-12 \mathrm{~cm} ; 2=19 \mathrm{~cm}$ or more $3=13-18$

\section{Fern pattern}

Ferning was graded according to the World Health Organisation scoring (WHO, 2010) by examination of cervical mucus that has been air-dried on glass microscope slides.

Based on WHO criteria, ferning is scored as follows: $0=$ no crystallization; 1 = atypical fern formation; $2=$ primary and secondary stem ferning; $3=$ tertiary and quaternary stem ferning.

Cervical mucus $p H$

The $\mathrm{pH}$ of cervical mucus was determined using indicator paper, range 5.5-9.0, immediately following aspiration. We applied our modification of Verma et als scoring method to evaluate the cervical mucus $\mathrm{pH}$ (Verma et al., 2014).

$\mathrm{pH}$ is scored as follows:

$0=<7$ or $>8.6 ; 1=8.1-8,5 ; 2=7.0-7.5 ; 3=7.6-8.0$

Statistical analysis

In this study, descriptive statistics were calculated a average scores of the physical characteristics of cervical mucus conception rate in cows and are presented in Mean \pm SEM format. The welch test and relative risk June 2021 | Volume 7 | Issue 1 | Page 60 were used to compare the different scores of physical properties of cervical mucus and their relationship with conception rate. Results were considered statistically significant at $\mathrm{P}<0.05$. Statistical analyses were performed using MedCalc Version 18 for Windows (MedCalc statistical software, Mariakerke, Belgium).

Results and Discussion

Cervical mucus specimen was evaluated for colour, viscosity, spinnbarkeit, fern pattern and $\mathrm{pH}$ from conceived and non-conceived cows. The outcomes of the scores of the physical characteristics of cervical mucus in conceived and non-conceived cows are presented in Table 1. The mean of all scores from conceived and non-conceived cows was 13.47 and 10.59. Comparison of cervical mucus score including all parameters demonstrated a significant $(\mathrm{P}<$ 0.0001) higher in conceived cows' mean score than non-conceived cows' mean score. All parameters of the cervical mucus score for non-conceived cows were less (Table 1$)$, with the change in viscosity $(\mathrm{P}<0.05)$, spinnbarkeit $(\mathrm{P}<0.01)$ and fern pattern $(\mathrm{P}<0.01)$ being significant. The percentages of conceived and non-conceived cows according to the scores regarding the physical characteristics of cervical mucus at the insemination time are shown in Table 2. The scores of cervical mucus during AI had an important effect on probability of conception. The highest conception rate was achieved in score 3 for all parameters of the cervical mucus. The percentages of the physical characteristics of cervical mucus according to their scores in conceived and non-conceived cows were presented in Table 3. The incidences of conception in the cow were found to be $0.00,0.00,5.26$ and 94.74, respectively, for the $0,1,2$ and 3 scores of the colour of the cervical mucus samples. The difference between the cervical mucus score 3 and other scores was significant. Pregnant cows based on the viscosity of the cervical mucus samples were observed in $0.00 \%$ of the cows in the 0 scores, $10.53 \%$ of the cows in the 1 score, $26.32 \%$ of the cows in the 2 scores and $65.16 \%$ of the cows in the 3 score. The conception rates in the 0,1,2 and 3 scores of spinnbarkeit of the cervical mucus among the cows that had conception showed as $0.00,10.53,15.79$ and $73.68 \%$, respectively. The cows conceived of $0.00,5.26,26.32$, and $68.42 \%$ in the Fern Pattern scores of the 0,1 , 2 and 3, respectively. The cows in the $0,1,2$ and 3 $\mathrm{pH}$ scores of the cervical mucus had 57.14, 41.67 and 


$\begin{array}{lllllll} & \text { Colour } & \text { Viscosity } & \text { Spinnbarkeit } & \text { Fern pattern } & \mathbf{p H} & \text { All parameters } \\ \text { Conceived } & 2.95 \pm 0.05 & 2.53 \pm 0,16 & 2.63 \pm 0.16 & 2.63 \pm 0.14 & 2.74 \pm 0.10 & 13.47 \pm 0.04 \\ \text { Non-conceived } & 2.65 \pm 0.15 & 1.82 \pm 0,29 & 1.71 \pm 0.28 & 2.00 \pm 0.21 & 2.41 \pm 0.17 & 10.59 \pm 0.04 \\ & \mathrm{P}=0.07 & \mathrm{P}=0.05 & \mathrm{P}=0.01 & \mathrm{P}=0.01 & \mathrm{P}=0.10 & \mathrm{P}<0.0001\end{array}$

the probability of conception by insemination of cows with high mucus scores including all parameters. The relative risk of pregnancy among the scores of cervical mucus at the time of insemination was significant $(\mathrm{P}<0.05)$. Cow insemination with score two and three of cervical mucus had more likely to result in pregnancy than ones with scores zero and one (Table 4). In general, score 3 in the studied physical characteristics of cervical mucus had a comparative advantage compared to fewer scores for the probability of conception. The modified cervical mucus scoring of the cows used in this study cannot be compared with the results of previous studies because of the differences in the scoring methods used and the components in which they are expressed. However, the results obtained are original in terms of the comparison of the gravidity of cows.

The colour of the normal cervical mucus appeared to be clear/transparent with slight cloudiness or translucent/cloudy. In none of the pregnant and nonpregnant cows, a dirty colour (score 0) of cervical mucus was observed. 83.33\% of cows were seen with clean mucus discharge (score 3 ). This could probably be explained by better reproductive health (Verma et al., 2014). A high percentage of clear cervical mucus has also been reported by studies (Damarany, 2020; Modi et al., 2011). The conception occurred in the $60 \%$ of cows that had a score 3 for colour. Simila findings have been reported by Bernardi et al. (2016) and Lim et al. (2014) for the cows with clear cervica mucus. Clear cervical mucus is suitable for sperm penetration and provides better pregnancy (Modi et al., 2011) While cervical mucus score was 1 in cows at the time of insemination, pregnancy did not occur which might be due to impaired penetration and progressive movement of spermatozoa (Verma et al., 2014). In this study, it was found that the transparent mucus at the oestrus is ideal for conception. There was conception the percent 94.74 of the cows in the score 3 of cervical mucus colour among conceived ones. The proper stage of oestrus and better reproductive health status may be the probable cause of higher conception rate in score 3 of cervical mucus.

Mildly viscous mucus discharge (score 3) was observed in majority of cows $(52.78 \%)$ at the time of insemination and these cows had the highest conception rate (63.16\%) compared to the other scores. On the other hand, thick, highly viscou $\left(0^{\text {th }}\right.$ score $)$ of mucus was observed in $8.33 \%$ of cows June 2021 | Volume 7 | Issue 1 | Page 62 and none of these cows conceived. These results are in agreement with Siregar et al. (2017). Increased viscosity adversely affects sperm swimming speeds and survival of spermatozoa (Zimmer and Riffell, 2011). Also, thick cervical mucus is preventing fertilization process by significantly affects sperm penetration ability because of differences in regulation of the glycoprotein molecules of cervical mucus (Dev et al., 1997). Contrary to the findings of this study, some studies observed thick viscosity of oestrus mucus in pregnant cows (Layek et al., 2013; Lim et al., 2014). The other reason for the differences in the findings might be that the animals are not in the same stage of oestrus due to differences in time of collection of the sample in all studies (Joshi et al., 2017). Pregnancy occurred in $94.74 \%$ of cows with a 3 score of cervical mucus viscosity among conceived ones. One cause of a higher conceiving in the 3 score of cervical mucus might be due to facilitate the migration of spermatozoa inside the female reproductive tract and form the cervical spermatozoa reservoir (Verma et al., 2014).

The spinnbarkeit score in the majority (55.56\%) of mucus samples was 3 at the time of insemination. The present find was in agreement with Parikh et al. (2018) who found that majority of oestrus in Gir cows had spinnbarkeit value of 8-16 cm. The results of the present study indicated a possible association between conceiving and spinnbarkeit scores of cervical mucus at the time of insemination. In pregnant animals, the mean spinnbarkeit score of oestrus mucus was significantly $(\mathrm{p}<0.05)$ higher $(2.63 \pm 0.16)$ than non-pregnant $(1.71 \pm 0.28)$. While pregnancy in cows having zero cervical mucus score for spinnbarkeit was not achieved, the highest pregnancy $70.0 \%$ was obtained in ones having 3 spinnbarkeit scores of cervical mucus. A higher conception rate in spinnbarkeit with a score of three may be due to an increase in the capacity of sperm to penetrate the cervical mucus. These results are in agreement with Ningwal et al. (2018) who observed higher spinnbarkeit in cervical mucus of cows that became pregnant than non-pregnant ones. Similarly, Rangnekar et al. (2002) notified spinnbarkeit of cervical mucus in the range of 12 to $18 \mathrm{~cm}$ in fertile estruses.

Our study demonstrated that the fern pattern scores of mucus at the time of artificial insemination were positively correlated with probability of conception
$30.56 \%(11) \quad 45.45 \%(5) \quad 54.55 \%(6)$ $63.89 \%$ (23) $60.87 \%$ (14) $39.13 \%(9)$
In our study, mucus colour, viscosity, and ferning properties were found to be the important factors, which establish the fitness of cervical mucus for the
occurrence of pregnancy in cows. There was a rising in 
among cows of apparently normal fertility. Pregnant animals had significantly $(p<0.01)$ higher score $(2.63 \pm 0.14)$ for fern pattern of oestrus mucus than non-pregnant $(2.00 \pm 0.21)$. In this study, a better conception rate in cows having a score of 3 of fern pattern was observed. A higher pregnancy rate in fern pattern score 3 may be due to facilitated movement of sperm as compared to other fern pattern scores. Similar findings are reported by Ningwal et al. (2018) who reported increased pregnancy rate in cows with typical arborisation pattern compared to those atypical patterns. The zero score of fern pattern wa not observed both in pregnant and non-pregnant cows. This finding is in agreement with Ningwal et al. (2018) who reported that none of the pregnant and non-pregnant animals had nil fern pattern.

The cows included in this study had alkaline $\mathrm{pH}$ of cervical mucus at the time of artificial insemination. This is well consistent with previous studies (Zaman difference $(\mathrm{p}=0.1)$ was found in the mean $\mathrm{pH}$ score of their cervical mucus at the time of artificia insemination from pregnant and non-pregnant cows. The highest pregnancy rates occurred when cows were inseminated at $\mathrm{pH}$ having the score 3 of cervical mucus. This might be due to improved progressive motility of spermatozoa and the appropriate uterine environment for the embryo. Hafeez and Hafeez (2000) reported that the acidity or excess alkalinity of the cervical mucus reduces sperm motility, thus leading to insufficiency of fertilization. In this study, there was a tendency for the $\mathrm{pH}$ values of the nonpregnant cows to be slightly more alkaline than the pregnant ones, but the difference was not significant The detrimental effect of high mucus $\mathrm{pH}$ at the time of artificial insemination on conceiving could be due to a direct effect of the $\mathrm{pH}$ on the sperm or an alteration of the structure of cervical mucus. In contrast to our findings, some earlier studies (Damarany, 2020; Ningwal et al., 2018) recorded more alkaline $\mathrm{pH}$ in the pregnant cow. Correa et al. (2001) demonstrated that the $\mathrm{pH}$ increases of cervical mucus due to the different times between the two measurements. Furthermore, it is notified that heat stress leads to changes in the physical and biochemical propertie of cervical mucus at the time of insemination (AbdElHafeez et al., 2020). This can also be related to whether the cows are under heat stress.

\section{Conclusions and Recommendations}

In conclusion, the results from the present study showed that the score by the physical characteristic of the cervical mucus could be used as a tool to be considered for the right moment to inseminate and to achieving an acceptable percentage of pregnancy. Mucus colour, viscosity, $\mathrm{pH}$, and ferning propertie were found to be the important factors, which establish the fitness of cervical mucus for the occurrence of pregnancy in cows. Alterations in score of physical characteristics of cervical mucus at the time of insemination may influence the chances of conception in cows. The scores of physical propertie of cervical mucus during artificial insemination can be used as an indicator for predicting conception.

\section{Novelty Statement}

Even though many researchers were worked on the cervical mucus, very few researchers were reported about the used score by the physical characteristics of the cervical mucus as an indicator for predicting conception. The study presents the alternative view with practice of cervical mucus used as a tool to be considered for the right moment to inseminate and to achieving an acceptable percentage of pregnancy.

Author's Contribution

The author collected the data, carried out the research, wrote, and revised the review paper.

Conflict of interest

The authors have declared no conflict of interest.

References

Abd-ElHafeez, A.M., Amin, A.M.S., Ramadan, M.H.,Helal,A. and Mohamed,M.Y.,2020.The most applicable physical properties of cervical mucus correlated with high pregnancy rate in egyptian cows under heat stress condition. Adv. Anim. Vet. Sci., 8(s2): 122-131. https://doi org/10.17582/journal.aavs/2020/8.s2.122.131

Beran, J., Stádník, L., Ducháček, J., Okrouhlá, M. Doležalová, M., Kadlecová, V. and Ptáček, M. 2013. Relationships among the cervical mucus urea and acetone, accuracy of insemination timing, and sperm survival in Holstein cows. Anim. Reprod. Sci., 142(1-2): 28-34. https://
Bernardi, S., Rinaudo, A., Marini, P., 2016. Cervical mucus characteristics and hormonal status at insemination of Holstein cows. Iran. J. Vet. Res., 17(1): 45-49.

Correa, C.H.M., Mattos, A.L.G. and Ferrari A.N. 2001. In situ variation of cervical mucus $\mathrm{pH}$ during exposure to atmospheric air. Braz. J. Med. Biol. Res., 34(6): 767-770. https://doi. org/10.1590/S0100-879X2001000600011

Damarany, A.I., 2020. Physical traits of vaginal mucus discharge and their relations to conception rate of egyptain baladi cows. Egypt. J. Anim. Prod., 57(2): 63-70. https://doi org/10.21608/ejap.2020.104019

Dev, S., Pangawkar, G.R., Sharma, R.K. and Verma, H.K., 1997. Sperm penetration in relation to physical characteristics of butfalo oestrual mucus. Int. J. Anim. Sci., 12: 89-91.

Hafeez,B.andHafeez,E.S.E.,2000.Reproduction in farm animals $7^{\text {th }}$ edn. Gopson papers Ltd, Noida. https://doi.org/10.1002/9781119265306

Hanumant, D., Tiwari, R.P., Chaturvedani, A.K. Paikra, D., Chandrakar, C. and Ratre, P., 2019. Analysis of corporeal characteristics of cervicovaginal mucus in cows. Pharma Innov. J., 8(3): 261-64.

Joshi, S.K., Mohanty, T.K., Bhakat, M. and Sathapathy, S., 2017. Characteristics of Cervical Mucus for Estrus Detection in Murrah Buffaloes (Bubalus bubalis). J. Anim. Res., 7(6): 1129-1134. https://doi.org/10.5958/2277940X.2017.00169.3

Layek, S.S., Mohanty, T.K., Kumaresan, A., Behera, K. and Chand, S., 2013. Cervical mucus characteristics and periestrual hormone concentration in relation to ovulation time in Zebu (Sahiwal) cattle. Livest. Sci., 152(23): 273-281. https://doi.org/10.1016/j livsci.2012.12.023

Lim, H.J., Son, J.K., Yoon, H.B., Baek, K.S., Kim, T.I., Jung. Y.S. and Kwon E.G., 2014 Physical properties of estrus mucus in relation to conception rates in dairy cattle. J. Embryo Transfer., 29(2): 157-161. https://doi. org/10.12750/JET.2014.29.2.15

Maher, M.A., Sayyed, T.M. and Elkhouly N., 2018 Cervical mucus removal prior to intrauterine insemination: a randomized trial. BJOG Int. J. Obstet. Gynaecol., 125(7): 841-847. https:// doi.org/10.1111/1471-0528.15003
Martyn, F., McAuliffe, F.M. and Wingfield, M. 2014. The role of the cervix in fertility: is it time for a reappraisal? Hum. Reprod., 29(10): 2092 2098. https://doi.org/10.1093/humrep/deu195

Modi, L.C., Suthar, B.N., Nakhashi, H.C., Sharma V.K. and Panchasara, H.H., 2011. Physical characteristic of estrual cervical mucus and conception rate in repeat breeder kankrej cattle. Int.J.Agro Vet.Med.Sci.,5(4): 416-423.https:// doi.org/10.5455/ijavms.20110801094641

Nakano, F.Y., Lea ${ }^{\sim}$ o, R.B.F. and Esteves, S.C., 2015. Insights into the role of cervical mucus and vaginal $\mathrm{pH}$ in unexplained infertility. Med. Exp., 2(2): 1-8. https://doi.org/10.5935/ MedicalExpress.2015.02.07

Ningwal, D., Nema, S.P., Kumar, S., Kushwah, A and Shivhare, M., 2018. Rheological properties of cervico-vaginal mucus in relation to fertility in crossbred cows and heifers. Int. J. Adv. Res., 6(6): 495-500. https://doi.org/10.21474/ IJAR01/7236

Parikh, S.S., Patbandha, T.K., Savaliya, B.D., Makwana, R.B., Raval, R.J. and Kapadiya, P.S. 2018. Association of estrous behaviour and cervical mucus properties with conception in Gir cows. J. Pharma. Phytochem., 7(s1): 31014.

Rangnekar, M.N., Dhoble, R.L., Gacche, M.G. Ingawale, M.V., Sawale, A.G. and Jadhav, J.M., 2002. Physical properties of oestrual mucus in repeat breeding crossbred (Holstein-Friesian) Cows with reference to fertility. Indian J. Anim. Sci., 72(12): 1122-1124.

Sharma, V.K. and Tripathi, S.S., 1987. Physiochemical properties of cervical mucus in relation to conception in normal and repeat breeding cross-bred cows. Indian J. Anim. Res., 8: 43-45.

Siregar, T.N., Agustina, I., Masyitah, D., Azhar, A., Dasrul, D., Thasmi, C.N., Sulaiman, R. and Daud, R., 2017. Physical properties of cervical mucus of repeat breeder Aceh cattle. J. Vet. 18(3): 378-382. https://doi.org/10.19087/ jveteriner.2017.18.3.378

Siregar, T.N., Armansyah, T., Panjaitan, B., Gholib, G., Herrialfian, H., Sutriana, A., Abidin, Z. Reynaldi, M.A., Razak, F. Artaliani, Y. and Yuswar, Y., 2019. Changes in cervical mucus as an indicator of fertility in Aceh cattle. Adv. Anim. Vet. Sci., 7(4): 306-314. https://doi. org/10.17582/journal.aavs/2019/7.4.306.314 Verma, K.K., Prasad, S., Kumaresan, A., Mohanty, 
T.K., Layek, S.S., Patbandha, T.K. and Chand, S., 2014. Characterization of physico-chemical properties of cervical mucus in relation to parity and conception rate in Murrah buffaloes. Vet. World, 7(7): 467-471. https://doi. org/10.14202/vetworld.2014.467-471

World Health Organization, 2010. WHO laboratory manual for the examination and processing of human semen 5 th edn., Geneva, Switzerland, WHO. pp. 248-249.
Zaman, M.I., Sharma, U., Kumar, S. and Kumar, S., 2013. Studies on physical properties of cervical mucus of repeat breeding crossbred cows. Indian J. Anim. Reprod., 34(2): 6-8.

Zimmer, R.K. and Riffell, J.A., 2011. Sperm chemotaxis, fluid shear, and the evolution of sexual reproduction. Proc. Natl. Acad. Sci. U.S.A., 108: 13200-13205. https://doi. org/10.1073/pnas.1018666108 